\title{
Evaluation of the $\mathrm{G}$ protein coupled receptor-75 (GPR75) in age related macular degeneration
}

\begin{abstract}
Christian G Sauer, Karen White, Heidi Stöhr, Tiemo Grimm, Amy Hutchinson, Paul S Bernstein, Richard Allan Lewis, Francesca Simonelli, Daniel Pauleikhoff, Rando Allikmets, Bernhard H F Weber
\end{abstract}

Institute of Human Genetics, University of Würzburg, Germany C G Sauer

K White

H Stöhr

T Grimm

B H F Weber

Departments of Ophthalmology and Pathology, Columbia University, New York, NY, USA

A Hutchinson

R Allikmets

Moran Eye Center, University of Utah, Salt Lake City, UT, USA

P S Bernstein

Departments of Ophthalmology and of Molecular and Human Genetics, Baylor College of Medicine, Houston, TX, USA

$\mathrm{R}$ A Lewis

Eye Clinic, Second University of Naples, Italy

F Simonelli

Augenabteilung, St Franziskus-Hospital, Münster, Germany D Pauleikhoff

Correspondence to: Bernhard H F Weber, Institute of Human Genetics, Biocenter, Am Hubland, D-97074 Würzburg, Germany

bweb@biozentrum. uni-wuerzburg.de

Accepted for publication 8 March 2001

\begin{abstract}
Background-A long term project was initiated to identify and to characterise genes that are expressed exclusively or preferentially in the retina as candidates for a genetic susceptibility to age related macular degeneration (AMD). A transcript represented by a cluster of five human expressed sequence tags (ESTs) derived exclusively from retinal cDNA libraries was identified.

Methods-Northern blot and RT-PCR analyses confirmed preferential retinal expression of the gene, which encodes a G protein coupled receptor, GPR75. Following isolation of the full length cDNA and determination of the genomic organisation, the coding sequence of GPR75 was screened for mutations in 535 AMD patients and 252 controls from Germany, the United States, and Italy. Employed methods included single stranded conformational polymorphism (SSCP) analysis, denaturing high performance liquid chromatography (DHPLC), and direct sequencing.

Results-Nine different sequence variations were identified in patients and control individuals. Three of these $(-30 A>C, 150 G>A$, and 346G $>A)$ likely represent polymorphic variants. Each of six alterations (-4G>A, N78K, P99L, S108T, T135P, and Q234X) were found once in single AMD patients and were considered variants that could affect the protein function and potentially cause retinal pathology.

Conclusion-The presence of six potential pathogenic variants in a cohort of 535 AMD patients alone does not provide statistically significant evidence for the association of sequence variation in GPR75 with genetic predisposition to AMD. However, a possible connection between the variants and age related retinal pathology cannot be discarded. Functional studies are needed to clarify the role of $G P R 75$ in retinal physiology.

(Br f Ophthalmol 2001;85:969-975)
\end{abstract}

One challenge in molecular genetic research today involves the discovery and characterisation of genes that underlie common disorders with complex patterns of inheritance. In ophthalmic genetics, such a challenge is posed by age related macular degeneration (AMD), which represents the most common cause of visual impairment in the population over 65 years of age. ${ }^{12}$ The disorder is characterised by retinal drusen, abnormal pigmentation of the retinal pigment epithelium (RPE), and geographic atrophy and/or choroidal neovascularisation in association with advancing age. ${ }^{3}$ Numerous environmental contributors such as sun exposure, ${ }^{4}$ hypertension, ${ }^{5}$ cigarette smoking, ${ }^{67}$ and dietary factors ${ }^{89}$ have been suggested; however, genetic predisposition appears to be the most important risk factor. ${ }^{10-12}$ Elucidation of the genetic components will lead to a better understanding of the pathophysiology of AMD and, in turn, may result in the development of novel preventive therapies.

Application of conventional gene identification approaches, such as positional cloning or positional candidate gene analysis, to identify genetic factors conferring susceptibility to AMD has been hampered by the considerable clinical heterogeneity of the condition even in the same family, by the scarcity of families with several living affected members due to the late age at onset, and by the lack of penetrance in younger members of families in which older individuals may manifest the trait. Thus, most studies to date have been limited to screening AMD patients for genetic variation in genes implicated in monogenic retinopathies with similar phenotypes (for a review, see Yates and Moore $^{13}$ ). Thus far, no associations have been found between AMD and the genes underlying several dominant Mendelian retinal disorders with either atrophic or disciform macular degeneration as a prominent feature: Sorsby fundus dystrophy, ${ }^{14}$ Best vitelliform macular dystrophy, ${ }^{15-17}$ and Doyne honeycomb retinal dystrophy/Malattia Leventinese. ${ }^{18}$ Screening of the photoreceptor specific ATP binding cassette transporter gene, $A B C A 4$ (formerly $A B C R)$, responsible for Stargardt disease, ${ }^{19}$ has revealed statistically significant association of at least two heterozygous mutations in $A B C A 4$ with AMD. ${ }^{20}{ }^{21}$ The extent of the contribution of these and other $A B C A 4$ variants to AMD remains to be determined; however, AMD associated genetic variation in $A B C A 4$ has been documented in a fraction of $A M D$ patients, suggesting the contributions of other yet unidentified genes. ${ }^{22}{ }^{23}$

We have initiated a long term project to characterise systematically a pool of genes that can be assessed for their role in predisposition to $\mathrm{AMD} .^{24}$ Reasoning that good candidates are those genes that are exclusively or preferentially expressed in the human retina, we searched the Unigene gene indexing database 
Table 1 Oligonucleotide primers used for analysing the GPR75 gene

\begin{tabular}{|c|c|c|c|c|c|}
\hline Amplicon & $\begin{array}{l}\text { Primer } \\
\text { name }^{\star}\end{array}$ & Sequence & $\begin{array}{l}\text { Size } \\
(b p)\end{array}$ & $\begin{array}{l}\text { Restriction enzyme } \\
\text { (sizes in bp) }\end{array}$ & $T_{A}\left({ }^{\circ} C\right)$ \\
\hline 1 & $\begin{array}{l}91 . \mathrm{R} 7 \\
91 . \mathrm{S} 4\end{array}$ & $\begin{array}{l}\text { 5'-TAATCCCTTTCTGTTTCTGG-3' } \\
\text { 5'-AGGACAAGAAGACAATGAAG-3' }\end{array}$ & 348 & Nla III $(201+147)$ & 53 \\
\hline 2 & $\begin{array}{l}\text { 91.R1 } \\
\text { 91.S8 }\end{array}$ & $\begin{array}{l}\text { 5'-ATCTCATCCACACAGCCAC-3' } \\
\text { 5'-CGATCACTGCCACTGTCTTC-3' }\end{array}$ & 318 & Mnl I (180+138) & 59 \\
\hline 3 & $\begin{array}{l}\text { 91.R2 } \\
91 . S 7\end{array}$ & $\begin{array}{l}\text { 5'-CCAGTTCAGGCTTCATCATC-3' } \\
\text { 5'-CCGGCATGGCACACTGGAT-3' }\end{array}$ & 439 & Acc I $(257+182)$ & 60 \\
\hline 4 & $\begin{array}{l}\text { 91.R3 } \\
\text { 91.S6 }\end{array}$ & $\begin{array}{l}\text { 5'-TGTGCAGGGAGGTGGAGAT-3' } \\
\text { 5'-AAACTGGTAAAGAATGAAGC-3' }\end{array}$ & 303 & Mnl I $(172+131)$ & 60 \\
\hline 5 & $\begin{array}{l}\text { 91.R4 } \\
\text { 91.S2 }\end{array}$ & $\begin{array}{l}\text { 5'-GTCCTGGTGTGCTGTCTTCC-3' } \\
\text { 5'-CTGTGGCTTTGGAGATAACA-3' }\end{array}$ & 327 & Hae III $(196+131)$ & 56 \\
\hline 6 & $\begin{array}{l}91 . \mathrm{R} 5 \\
91 . \mathrm{S} 1\end{array}$ & $\begin{array}{l}\text { 5'-CAGAAACAAATCCTCCCATC-3' } \\
\text { 5'-TCTGCTTGGCTGAAGTGCTG-3' }\end{array}$ & 349 & Alu I $(190+159)$ & 60 \\
\hline 7 & $\begin{array}{l}\text { 91.R9 } \\
\text { 91.S11 }\end{array}$ & $\begin{array}{l}\text { 5'-AACTCTTTTGGATTTGCC-3' } \\
\text { 5'-GAAAGAAAACCATAACTGCC-3' }\end{array}$ & 248 & - & 54 \\
\hline
\end{tabular}

*PCR conditions were $94^{\circ} \mathrm{C}, 5$ minutes; 30 cycles of $94^{\circ} \mathrm{C}, 30$ seconds, $\mathrm{T}_{\mathrm{A}}, 30$ seconds, $72^{\circ} \mathrm{C}, 30$ seconds; $72^{\circ} \mathrm{C}, 5$ minutes. of the insert was determined with the Thermo Sequenase radiolabelled terminator cycle sequencing kit (Amersham, Life Science). To extend the resulting sequence to the transcription start site, 5'-RACE was performed on total human retinal RNA with the 5'-RACE kit, Version 2 (Gibco BRL). First strand cDNA synthesis with primer 91.S8 (Table 1) was followed by two subsequent PCR reactions with nested primers 91.S4 (Table 1) and 91.S5 (5'TGC TCC CCA AAA ATA CTC AG-3'). The resulting PCR products were separated electrophoretically on an agarose gel, excised, purified with the QIAexII Gel Extraction Kit (Qiagen), and sequenced directly. To obtain the genomic sequence, we screened the RCPI-1 PAC library (kindly provided by $\mathrm{P}$ de Jong, Roswell Park Cancer Institute, Buffalo, NY) with a radiolabelled $2057 \mathrm{bp}$ cDNA insert from IMAGE clone 222124. Positive PAC clone dJ302H14 was partially sequenced and the genomic, and cDNA sequences were aligned with MacVector Sequence analysis program Version 4.1.4 (Kodak) to determine the exon-intron structure (Fig 1). We subjected the deduced protein sequence to homology searches with the BLASTP program (http:// http://www.ncbi.nlm.nih.gov/BLAST/) and used the тмнмм program of the Husar package (http://genome.dkfz-heidelberg.de/) for prediction of the transmembrane domains.

duction and are involved in diverse hereditary and sporadic diseases (reviewed by Strader et $\left.a l^{26}\right)$. Because the expression profile and potential functional properties made it a candidate for involvement in $\mathrm{AMD}$, we screened it for mutations in a large cohort of affected individuals and ethnically and age matched controls.

\section{Materials and methods}

CDNA CLONING AND DETERMINATION OF GENE STRUCTURE

A cluster of five EST sequences derived from three different retinal cDNA clones (IMAGE clone nos 222124, 363848, 363252) was retrieved under accession number Hs.40763 as part of a search under the term "eye" in the Unigene Human Sequences Collection (http:// www.ncbi.nlm.hih.gov/Unigene) ${ }^{24} \quad$ cDNA IMAGE clone 222124 was obtained from the UKHGMP Resource Centre (Hinxton, Cambridge, UK), and the complete DNA sequence

\section{EXPRESSION ANALYSES}

RT-PCR was performed as described previously. ${ }^{24}$ Briefly, total RNA was extracted from human liver, lung, uterus, cerebellum, brain stem, prostate, retinal pigment epithelium, and retina tissue with the RNA Clean system (Hybaid). After treatment with the DNA-free kit (Ambion) to remove residual genomic DNA, 1-2 $\mu$ l volumes of each preparation and 1-2 $\mu \mathrm{l}$ volumes of commercially obtained total RNA from heart, kidney, placenta, and thymus (Ambion) were reverse transcribed with the BRL), diluted 1:5, and subjected to PCR with oligonucleotide primers 91.S4 (Table 1) and 91.R13 (5'-GGT CCG GAC TGC GAG ATG-3') resulting in a 357 bp product. To normalise for variations in the amount of input RNA and synthesised cDNA from each tissue, control PCR reactions were conducted on $2 \mu \mathrm{l}$ Superscript preamplification system (Gibco

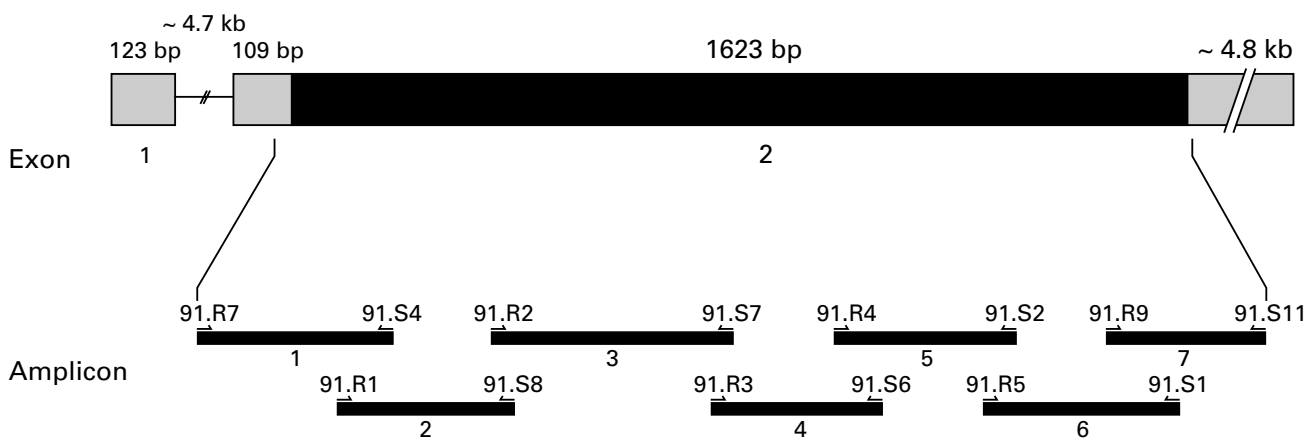

Figure 1 Diagrammatic representation of the genomic organisation of GPR75 and PCR amplification of the coding region of the gene. The exon/intron structure is given in relative spacing with coding sequences and untranslated regions represented by black and shaded boxes, respectively. Mutation analysis of the $1623 \mathrm{bp}$ of coding sequences was done with overlapping amplicons as indicated. Primer sequences and PCR conditions are given in Table 1. 
A

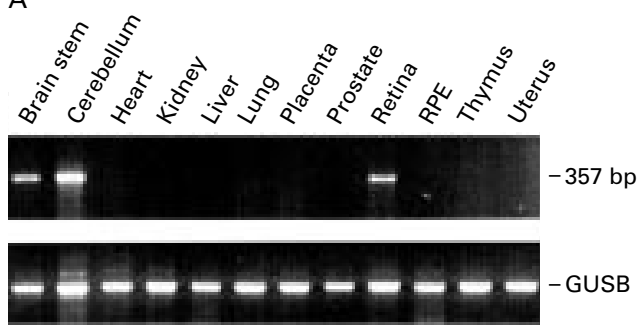

B

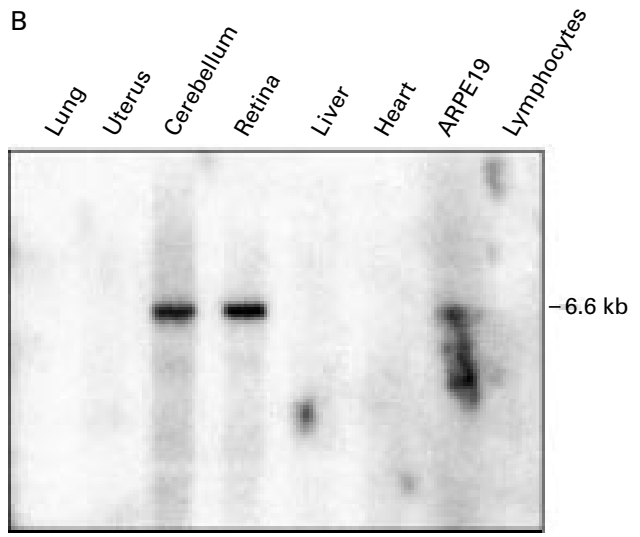

Figure 2 Expression analysis of GPR75. (A) RT-PCR showing expression in retina and brain tissue and $(B)$ northern blot detecting a $6.6 \mathrm{~kb}$ transcript in human cerebellum and retina.

of diluted first strand cDNA with primer pair GUSB6F (5'-GAT CCA CCT CTG ATG TTC AC-3') and GUSB7R (5'-CCT TTA GTG TTC CCT GCT AG-3') amplifying the constitutively expressed $\beta$ glucuronidase (GUSB) gene. ${ }^{27}$ The GUSB6F/GUSB7R amplification spans exon 11 and 12 of the human gene and results in a $454 \mathrm{bp}$ fragment in cDNA template.

For northern blot analysis, total RNA was isolated from human lung, cerebellum, retina, uterus, liver, heart, peripheral blood lymphocytes, and a human RPE cell line (ARPE19) with the RNA Clean System (Hybaid). In each lane $12 \mu \mathrm{g}$ of total RNA was separated electrophoretically in a $1.2 \%$ agarose gel in the presence of formaldehyde and blotted onto a nylon membrane. A $615 \mathrm{bp}$ PCR fragment amplified from IMAGE clone 222124 with oligonucleotide primer pair 91.R4/91.S1 (Table 1) and a $270 \mathrm{bp}$ fragment amplified from PAC clone dJ302H14 with the oligonucleotide primers 3UTR-F (5'-AAG TGG AAA TGG GCA GAA AG-3') and 3UTR-R (5'-TTA CGC AAA GGA ACA AAG-3') were used for filter hybridisations in $0.5 \mathrm{mM}$ sodium phosphate buffer, $\mathrm{pH} 7.2 ; 7 \%$ SDS, $1 \mathrm{mM}$ EDTA at $65^{\circ} \mathrm{C} .^{28}$

MUTATION ANALYSIS

Subjects

A total of 535 individuals with AMD and 252 unaffected controls, matched by age and ethnicity were studied. These subjects have been ascertained in Germany, the United States, and Italy and have been described previously as part of an international consortium study screening for mutations in the $A B C A 4$ gene. ${ }^{21}$ The diagnosis of AMD is based on internationally accepted criteria ${ }^{3}$; an approximately equal ratio of exudative to atrophic AMD is represented in the patient group. Most patients and controls have been studied in the $V M D 2^{1516}$ and $A B C A 4^{2122}$ genes.

\section{Mutation analysis}

Genomic DNA was isolated from the peripheral blood of AMD patients and control individuals by standard techniques. The entire coding sequence of the gene and its flanking 5 'and 3'-untranslated region (UTR) were PCR amplified in seven segments with the oligonucleotide primer pairs shown in Figure 1 and listed in Table 1.

A total of 198 German patients and 101 matched controls were screened for mutations with single stranded conformational polymorphism (SSCP) analysis. PCR amplification was carried out with Taq-Polymerase (Life Technologies) in a $25 \mu \mathrm{l}$ volume with $1 \times$ PCR buffer supplied by the manufacturer. To increase sensitivity of the SSCP analysis, the PCR products were digested with appropriate restriction enzymes to yield fragments $<260 \mathrm{bp}$ (Table 1). Radiolabelled PCR products were separated electrophoretically on a $6 \%$ nondenaturing polyacrylamide gel with or without $5 \%$ glycerol at $4^{\circ} \mathrm{C}$. DNA fragments displaying mobility shifts were sequenced directly.

In all, 241 US and 96 Italian patients, and 112 US and 39 Italian controls were screened by DHPLC. PCR samples were separated on a DNASep column (Transgenomic, Omaha, NE, USA) on a Helix HPLC system (Varian Instruments, Walnut Creek, CA, USA), with the standard program supplied by the manufacturer (Varian).

\section{Exon trapping}

The effect of the $150 \mathrm{G}>\mathrm{A}$ transition on RNA splicing was evaluated in an exon trapping system as described by Rivera et al..$^{22}$ Briefly, a 333 bp exonic fragment encompassing this alteration was PCR amplified from the DNA of German AMD patient No 107 with oligonucleotide primers R1-EcoRI-F (5'-CCG GAA TTC ATC TCA TCC ACA CAG CCA C-3') and S8-BamHI-R (5'-CGC GGA TCC CGA TCA CTG CCA CTG TCT TC-3'). Constructs carrying the normal $150 \mathrm{G}$ and the mutant 150A allele were selected and transfected into COS-7 cells. After a 48 hour culture, the cells were harvested and total RNA was extracted. Two different RT-PCR experiments were performed, the first with two vector primers, SD6 (5'-TCT GAG TCA CCT GGA CAA CC-3') and SA2 (5'-ATC TCA GTG CTA TTT GTG AGC-3'), and the second with vector primer SD6 and exonic primer 91.s4 (Table 1). As positive control we analysed a mutant splice acceptor site (IVS20+5G $>A$ ) that has a known effect on the $A B C A 4$ transcript. ${ }^{22}$

\section{Statistical analysis}

To test statistically whether there is a relation between two categorical variables the Fisher's exact test was used (http://www.matforsk.no/ ola/fisher.htm). The sample size required to 
Table 2 Sequence alterations in GPR75 detected in 535 AMD patients and 252 controls

\begin{tabular}{|c|c|c|c|c|c|c|c|c|}
\hline Amplicon & $\begin{array}{l}\text { Nucleotide } \\
\text { change }\end{array}$ & $\begin{array}{l}\text { Amino acid } \\
\text { change }\end{array}$ & $\begin{array}{l}\text { AMD alleles } \\
(G E R)(n=396)\end{array}$ & $\begin{array}{l}\text { Control alleles } \\
(G E R)(n=202)\end{array}$ & $\begin{array}{l}\text { AMD alleles } \\
(U S A)(n=482)\end{array}$ & $\begin{array}{l}\text { Control alleles } \\
\text { (USA) }(n=224)\end{array}$ & $\begin{array}{l}\text { AMD alleles } \\
\text { (ITA) }(n=192)\end{array}$ & $\begin{array}{l}\text { Control alleles } \\
\text { (ITA) }(n=78)\end{array}$ \\
\hline 1 & $-30 \mathrm{~A}>\mathrm{C}$ & - & $27(6.8 \%)$ & $14(6.9 \%)$ & $44(9.1 \%)$ & $13(5.8 \%)$ & $14(7.3 \%)$ & $5(6.4 \%)$ \\
\hline 1 & $-4 \mathrm{G}>\mathrm{A}$ & - & 0 & 0 & $1(0.2 \%)$ & 0 & 0 & 0 \\
\hline 1 & $150 \mathrm{G}>\mathrm{A}$ & A50A & $1(0.3 \%)$ & 0 & $2(0.4 \%)$ & $1(0.5 \%)$ & 0 & 0 \\
\hline 2 & $234 \mathrm{C}>\mathrm{G}$ & N78K & $1(0.3 \%)$ & 0 & 0 & 0 & 0 & 0 \\
\hline 2 & $296 \mathrm{C}>\mathrm{T}$ & P99L & 0 & 0 & $1(0.2 \%)$ & 0 & 0 & 0 \\
\hline 2 & $323 \mathrm{G}>\mathrm{C}$ & S108T & 0 & 0 & $1(0.2 \%)$ & 0 & 0 & 0 \\
\hline 2 & $346 \mathrm{G}>\mathrm{A}$ & A116T & $5(1.3 \%)$ & $2(1.0 \%)$ & $11(2.3 \%)$ & $3(1.3 \%)$ & $15(7.8 \%)$ & $4(5.1 \%)$ \\
\hline 2 & $403 \mathrm{~A}>\mathrm{C}$ & T135P & 0 & 0 & $1(0.2 \%)$ & 0 & 0 & 0 \\
\hline 3 & $700 \mathrm{C}>\mathrm{T}$ & Q234X & $1(0.3 \%)$ & 0 & 0 & 0 & 0 & 0 \\
\hline
\end{tabular}

statistically detect a difference between our findings in AMD patients and controls at a given power was computed using an interactive web site at http://members.aol.com/johnp71/ proppowr.html. The calculations incorporate a continuity correction to the usual sample size formula based on the normal approximation to the binomial distribution. ${ }^{29}$

\section{Results}

CHARACTERISATION OF THE HUMAN G PROTEIN COUPLED RECEPTOR-75 (GPR75)

The expression pattern in vitro of the transcript represented by Unigene cluster Hs. 40763 was determined by RT-PCR with a panel of first strand cDNA from 12 human tissues. Using oligonucleotide primers designed from IMAGE clone 222124, we amplified a $357 \mathrm{bp}$ fragment from cDNA from retina, brain stem, and cerebellum (Fig 2A). No amplification products were detected in any other tissues, suggesting neuronal expression of the transcript with the major sites of expression in retina and brain.

Of the five EST sequences comprising the cluster, two derive from IMAGE clone 222124. Sequencing the full length of the clone insert resulted in a $2057 \mathrm{bp}$ sequence containing an ATG start codon in a weak context (cgaaaATGA $)^{30}$ followed by an open reading frame of $1623 \mathrm{bp}$. An in-frame stop codon was localised $45 \mathrm{bp}$ upstream of ATG. We were able to extend the sequence $19 \mathrm{bp}$ with 5'-RACE. Alignment with genomic sequence revealed that the gene consists of two exons, at least $123 \mathrm{bp}$ and $1732 \mathrm{bp}$ in length, with the entire coding sequence contained within the larger second exon (acc nos AF303576, AF 101472) (Fig 1). The two exons are separated by an intron of approximately $4.7 \mathrm{~kb}$ with the 5'-donor (. . .CAGgtgaga . . .) and 3'-acceptor splice site (. . .gcatttttgtgtgtagG ...) conforming to conserved sequences required for proper binding of the active spliceosome. The predicted protein product consists of 540 amino acids, has seven transmembrane domains and shows homology to the superfamily of $\mathrm{G}$ protein coupled receptors (Fig 3).

We investigated the expression profile further by northern blot analysis. Probing with a $615 \mathrm{bp}$ fragment PCR amplified from IMAGE clone 222124 revealed a $6.6 \mathrm{~kb}$ transcript in human cerebellum and retina (Fig 2B). Expression was not detected in lung, the RPE19 cell line, uterus, liver, heart, or peripheral blood leucocytes (Fig 2B). The same results were obtained with a 270 bp sequence amplified from PAC clone $\mathrm{dJ} 302 \mathrm{H} 14$ probe and located approximately $2.3 \mathrm{~kb}$ downstream of the stop codon (TAA) (data not shown), demonstrating that the transcript contains a

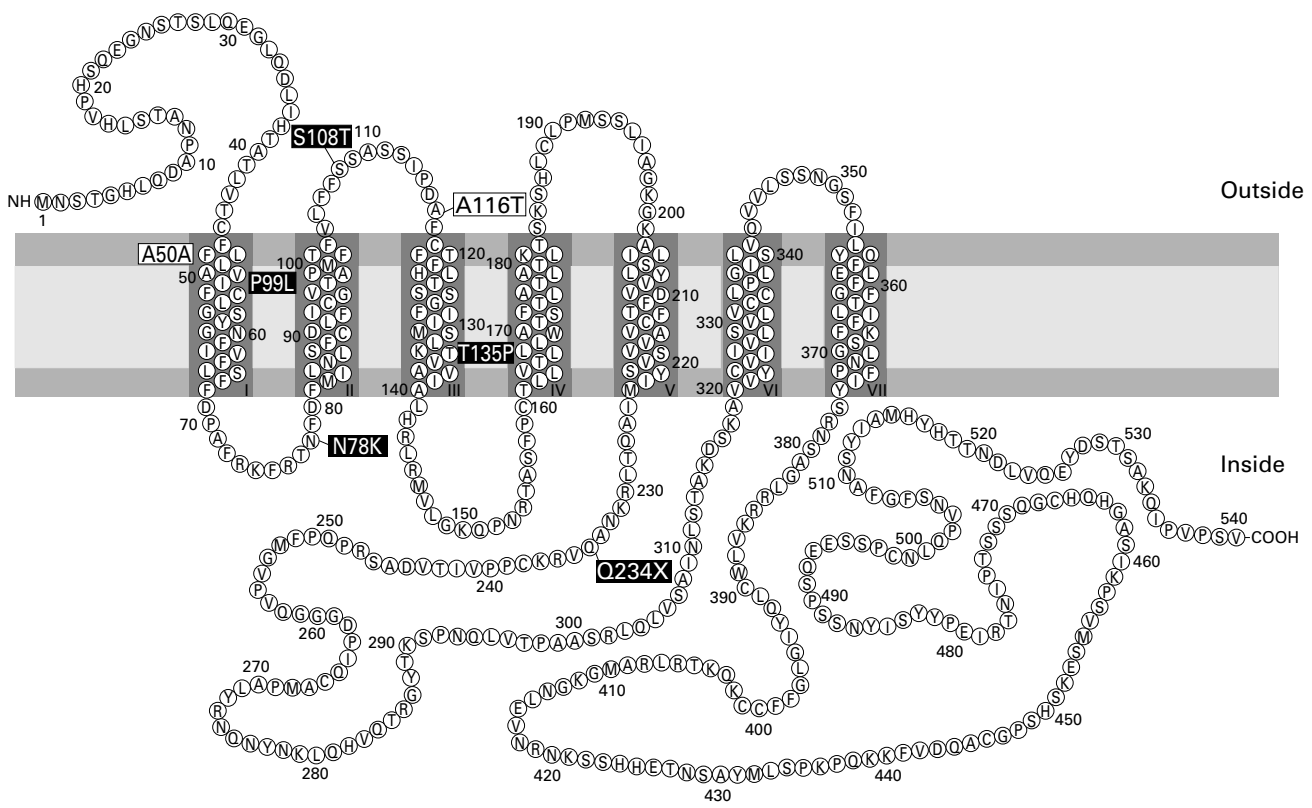

Figure 3 Schematic representation of the GPR75 protein showing the seven putative transmembrane domains and the locations of the amino acids affected by the five potentially disease associated variants (black boxes) and two likely polymorphisms (white boxes). Each circle represents a single amino acid. 


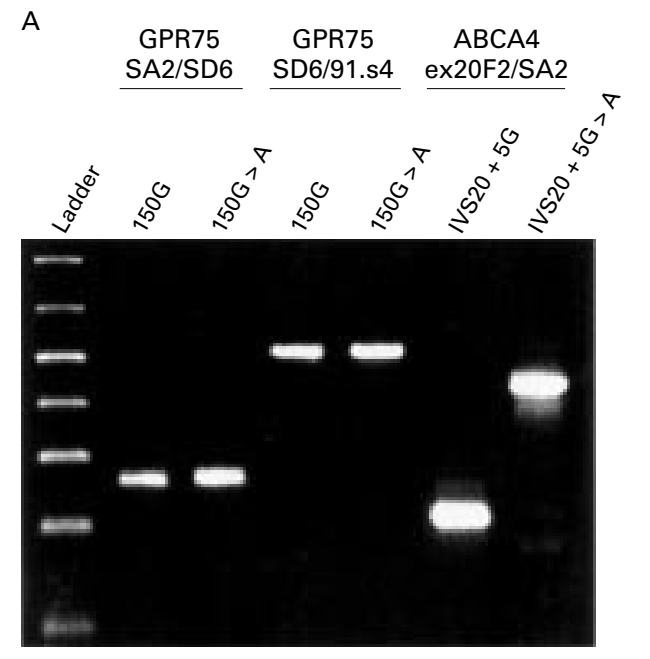

B

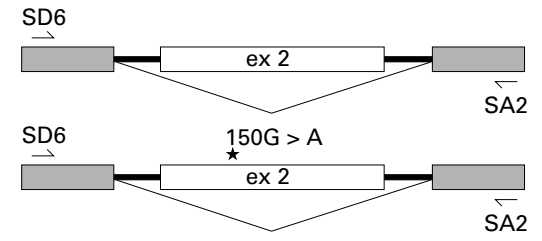

C

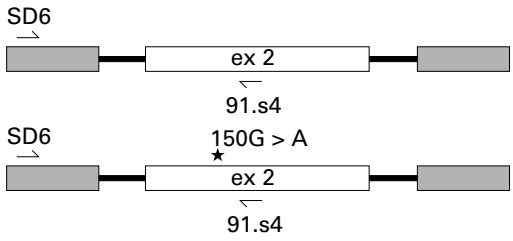

$\mathrm{D}$

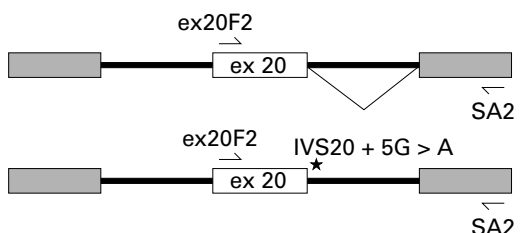

Figure 4 Evaluation of the consequences of alteration 150G>A. (A) Results of RT-PCR analyses showing identical splicing products from both wild type and mutant sequences. The positive control (mutation IVS20+5G>A in the ABCA4 gene) demonstrates differential splicing between wild type and mutant sequences. A 100 bp sizing ladder, spanning 100-700 $b p$, is given. (B-D) Diagrams demonstrating the observed splicing with the position of oligonucleotide primers (half arrows) and mutant sites (asterisks) shown.

large 3'-UTR which has not yet been characterised in its entirety.

MUTATION ANALYSIS

SSCP or DHPLC analysis of the entire coding sequence of the GPR75 gene (Fig 1) was performed in 535 unrelated AMD patients and 252 age and ethnically matched controls from Germany, the United States, and Italy. This analysis identified nine different sequence alterations (Table 2 and Fig 3). Six of these were found in single AMD patients but not in control individuals. These include a guanine to adenine transition at position -4 of the UTR $(-4 \mathrm{G}>\mathrm{A})$, three alterations leading to nonconservative amino acid substitutions (N78K, P99L, T135P), one alteration leading to a conservative amino acid substitution (S108T), and one nonsense mutation, a $\mathrm{C}$ to $\mathrm{T}$ transition creating a premature stop at codon 234 (Q234X). Analysis of DNA obtained from four unaffected sons (aged 36-48 years) of the German AMD patient (No 95) with the Q234X mutation revealed that one has inherited the mutation but, at age 47 , had a normal ophthalmological examination including the retinas (data not shown). Three alterations were found in both AMD patients and control individuals. Two of these, an adenine to cytosine transversion at position -30 in the $5^{\prime}-\mathrm{UTR}(-30 \mathrm{~A}>\mathrm{C})$ and a guanine to adenine transition at nucleotide position 346 leading to a putative non-conservative amino acid substitution (A116T), were found in frequencies of $7.4 \%$ (117/1574 alleles) and 2.5\% (40/1574 alleles), respectively. The frequencies of each of the variants were not significantly different between the AMD and the control group $(-30 \mathrm{~A}>\mathrm{C}: \mathrm{p}=0.26 ; \mathrm{A} 116 \mathrm{~T}: \mathrm{p}=0.19)$. A third change involving a $G$ to $A$ substitution at nucleotide position 150 (150G>A) was found in one German AMD patient, two US AMD patients, and one US control. This alteration does not affect the amino acid sequence but does introduce the dinucleotide AG into the DNA sequence downstream from a stretch of pyrimidine residues.

To determine whether the $150 \mathrm{G}>\mathrm{A}$ alteration could create a cryptic acceptor splice site, we used an exon trapping system to present exonic sequence corresponding to the wild type and mutant alleles to the splicing machinery in COS7 cells. RT-PCR amplification with vector specific oligonucleotide primers SD6 and SA2 yielded the same $261 \mathrm{bp}$ fragment from both the wild type and mutant clones (Fig 4A, B). Direct DNA sequencing confirmed that both fragments are composed of only vector sequence with both inserts spliced out as a result of vector related splice donor and acceptor sites. A second RT-PCR experiment was performed with vector primer SD6 and exonic primer 91.s4. The exonic primer precludes the amplification of the predominant splice product and should allow the detection of low abundance transcripts. The second experiment amplified a $505 \mathrm{bp}$ fragment both from normal and from wild type clones (Fig 4A, C). This large fragment is completely unspliced and includes the full insert and flanking vector sequences. The predicted $138 \mathrm{bp}$ fragment from the hypothetical cryptic splice site was not observed. In the positive control, differential splicing was observed between the mutant IVS $20+5 \mathrm{G}>\mathrm{A}$ and the wild type sequence in the $A B C A 4$ gene (Fig $4 \mathrm{~A}, \mathrm{D}$ ).

\section{Discussion}

In our programme to establish a comprehensive catalogue of retinal genes with a possible 
predisposition to AMD, we identified a cluster of five EST sequences derived exclusively from retinal cDNA libraries. The in silico expression profile was expanded by in vitro studies demonstrating expression in retina and brain tissues. Analysis of the full length transcript and the respective genomic sequence revealed a two exon gene, named GPR75, that codes for a member of the superfamily of $G$ protein coupled receptors. During the course of our work GPR75 was cloned independently in the effort to identify the gene for Doyne honeycomb retinal dystrophy (DHRD) and Malattia Leventinese (ML) on chromosome $2 \mathrm{p} 16 .{ }^{31}$ Mutation analysis in GPR75, however, revealed that this gene is not underlying the $\mathrm{DHRD} / \mathrm{ML}$ phenotype. ${ }^{31}$ A single ancestral mutation has since been identified in a neighbouring gene, the EGF containing fibulin-like extracellular matrix protein-1 (EFEMP1), in affected individuals in DHRD and ML families. ${ }^{18}$

The potential functional properties of GPR75 as a G protein coupled receptor in the retinal tissue make it a candidate for association with the AMD phenotype. We have studied the entire coding region and the flanking splice site, 5'-UTR and 3'-UTR sequences in 535 unrelated AMD patients and 252 matched controls. The analysis identified a total of nine different sequence alterations of which three likely represent polymorphic changes. Two of these, $-30 \mathrm{~A}>\mathrm{C}, 346 \mathrm{G}>\mathrm{A}$, are present in comparable frequencies in AMD patients and control individuals. The third variant (150G $>A)$, found in three AMD patients and one control, was evaluated in an exon trapping system for its potential to introduce a cryptic splice site; however, no effect on splicing was observed. This still leaves uncertainty about the potential effect of this alteration on gene function. Another alteration $(-4 G>A)$ found in a single American AMD patient is also of uncertain significance. This variant occurs close to the putative ATG start codon but may not alter this codon (cgaaaATGA) substantially, which is already in weak context compared to the Kozak consensus sequence. ${ }^{30}$ The remaining five alterations, found in single AMD patients, potentially could have adverse effects on the protein (N78K, P99L, S108T, T135P, Q234X). All the amino acid substitutions affect residues that are in or close to the putative transmembrane domains, regions that are involved in either ligand binding and/or G protein activation in other $G$ protein coupled receptors. ${ }^{26}$ Furthermore, P99L and T135P involve the removal and the addition, respectively, of proline residues, which are known to induce bends or folds into polypeptide chains and could therefore have serious consequences for the protein's three dimensional structure. The stop mutation (Q234X) occurs in the large intracellular loop between the putative transmembrane domains $\mathrm{V}$ and VI and results in the deletion of a substantial portion of the protein, predictably most of this loop, two transmembrane domains, and the entire intracellular C terminal end of the receptor.

While final proof of causality is lacking, we cannot eliminate the possibility that some
GPR75 mutations are involved in the observed retinal pathology in these rare instances. Consequently, a low fraction of AMD cases might occur from GPR75 mutations. The histories of the five patients with potential deleterious changes in the protein showed that four, German patients No 88 and No 95 and US patients No 119 and No 26554, have extensive soft drusen, retinal pigment epithelial detachments, and disciform macular degeneration. The US patient No 26037, who harbours a conservative amino acid substitution (S108T), has a different clinical picture with geographic atrophy and a positive family history of AMD. Interestingly, this patient is also heterozygous for the $\mathrm{D} 2177 \mathrm{~N}$ variant in the $A B C A 4$ gene $^{21}$ although the concomitant appearance of these two variants has no clear implication on the issue of association or causality. The ages of onset of visual symptoms associated with macular degeneration in the five patients range from 63 to 85 years, and one heterozygous carrier, the son of patient No 95, had no retinal abnormalities by examination at age 47 .

The results of this study are comparable to previous analyses of AMD patients in the $V M D 2$ gene, that underlies juvenile onset vitelliform macular dystrophy (Best disease). ${ }^{32} 33$ Two different studies have found similar low frequencies $(1-1.5 \%)$ of VMD2 mutations in AMD patients. ${ }^{1517}$ It is unclear, however, whether specific VMD2 mutations lead to an AMD phenotype or whether these findings provide evidence for substantial clinical heterogeneity in Best disease with some milder cases misdiagnosed as AMD at later stages of the disease. Supporting the latter interpretation is the demonstration of identical VMD2 mutations in patients with Best disease and in individuals with adult vitelliform macular dystrophy, a phenotypically similar but later onset condition. ${ }^{15}{ }^{16}$ Unlike VMD2, however, mutations in GPR75 have not been associated previously with a retinal phenotype. As a consequence of the selection of genes based on their expression profile rather than an association with an hereditary retinal disorder, we have no information regarding the disease causing potential of GPR75.

Support for an association between GPR75 variation and AMD may require screening of even larger cohorts of AMD patients and controls. If we consider the variants which are detected in our study with a frequency of less than $1 \%$ in all groups tested, we are left with nine sequence alterations in $535 \mathrm{AMD}$ patients (frequency of $0.84 \%$ ) and one variant in 252 controls (frequency of $0.2 \%$ ). With a power of only $16 \%$ these data do not reach statistical significance $(p=0.12$; one sided Fisher's exact test). To reach a power of $80 \%$ (at $\alpha=0.05$ ), the testing of approximately 1899 patients and 894 controls would be required. On the other hand, to find association with our present sample size (535 patients and 252 controls) and with the given frequency of the identified variations in the control population $(0.2 \%)(\alpha=$ 0.05 with $80 \%$ power), the frequency of variants in the patient sample would need to be 
10 times higher (2\%) than in the control population - that is, the sample size analysed in the present study has ample power to detect an association that is $2 \%$ or greater. The need to analyse large cohorts to achieve sufficient statistical power to accept or reject the hypothesis of an association of any disease allele with $\mathrm{AMD}$ has also been shown previously in the analysis of the $A B C A 4$ gene (for a review, see Allikmets $^{34}$ ).

Future investigations include identification of the ligand and the effector molecule(s) and the characterisation of the function of the GPR75 receptor in the human retina. In addition to clarification of any potential role of GPR75 in AMD, this information may also lead to the discovery of its role in other retinal phenotypes.

Sincere appreciation is extended to the individuals and families described herein and their attending physicians for their willing and continued participation in these studies. This work was supported in part by grants from the Deutsche Forschungsgemeinschaft (DFG), We 1259/11-1, the Bundesministerium für Bildung und Forschung (BMBF) under 01KW9921, The Foundation Fighting Blindness (Hunt Valley, MD, USA), Research to Prevent Blindness (New York, NY, USA), and The Ruth and Milton Steinbach Fund (New York, NY, USA). RAL is a senior scientific investigator of Research to Prevent Blindness, Inc.

1 Hyman L. Epidemiology of eye disease in the elderly. Eye $1987 ; \mathbf{1}: 330-41$

2 Evans J, Wormwald R. Is the incidence of registrable age-related macular degeneration increasing? $\mathrm{Br} \mathcal{F} O$ phthalmol 1996;80:9-14.

3 Bird AC, Bressler NM, Bressler SB, et al. An international classification and grading system for age-related maculopathy and age-related macular degeneration. The Interthy and age-related macular degeneration. The Intermol 1995;39:367-74.

4 Darzins P, Mitchell P, Heller RF. Sun exposure and Darzins P, Mitchell P, Heller RF. Sun exposure and age-related macular degeneration. An Aust
control study. Ophthalmology 1997;104:770-6.

5 Klein R, Klein BE, Jensen SC. The relation of cardiovascular disease and its risk factors to the 5 -year incidence of age-related maculopathy: the Beaver Dam Eye Study. Ophthalmology 1997;104:1804-12.

6 Christen WG, Glynn RJ, Manson JE, et al. A prospective study of cigarette smoking and risk of age-related macular degeneration in men. $\mathcal{F} A M A$ 1996;276:1147-51.

7 Seddon JM, Willett WC, Speizer FE, et al. A prospective study of cigarette smoking and age-related maculopathy. The Blue Mountains Eye Study. Arch Ophthalmol 1996, 114:1518-23.

8 Seddon JM, Ajani UA, Sperduto RD, et al. Dietary carotenoids, vitamins A, C, and E, and advanced age-related macular degeneration. Eye Disease Case-Control Study macular degeneration. Eye Disease

9 Marles-Perlman JA, Brady WE, Klein R, et al. Dietary fat and age-related maculopathy. Arch Ophthalmol 1995;113: and age-re.

10 Klein ML, Mauldin WM, Stoumbos VD. Heredity and agerelated macular degeneration. Observations in monozygotic twins. Arch Ophthalmol 1994;112:932-7.

11 Seddon JM, Ajani UA, Mitchell BD. Familial aggregation of age-related maculopathy. Am F Ophthalmol 1997;123:199206
12 Klaver CC, Wolfs RC, Assink JJ, et al. Genetic risk of lave-related maculopathy. Population-based familial aggregation study. Arch Ophthalmol 1998;116:1646-51.

13 Yates JRW, Moore AT. Genetic susceptibility to age related macular degeneration. $\mathcal{f}$ Med Genet 2000;37:83-7.

14 Felbor U, Doepner D, Schneider U, et al. Evaluation of the gene encoding the tissue inhibitor of metalloproteinases-3 (TIMP3) in various macular dystrophies. Invest Ophthalmol Vis Sci 1997;38:1054-9.

15 Allikmets R, Seddon JM, Bernstein PS et al. Evaluation of the Best disease gene in patients with age-related macular degeneration and other maculopathies. Hum Genet 1999; 104:449-53.

16 Krämer F, White K, Pauleikhoff D, et al. Mutations in the VMD2 gene are associated with juvenile-onset vitelliform macular dystrophy (Best disease) and adult vitelliform macular dystrophy but not age-related macular degeneration. Eur f Hum Genet 2000;8:286-92.

17 Lotery AJ, Munier FL, Fishman GA, et al. Allelic variation in the VMD2 gene in best disease and age-related macular degeneration. Invest Ophthalmol Vis Sci 2000;41:1291-6.

18 Stone EM, Lotery AJ, Munier FL, et al. A single EFEMP1 mutation associated with both Malattia Leventinese and Doyne honeycomb retinal dystrophy. Nat Genet 1999;22: 199-202.

19 Allikmets R, Singh N, Sun H, et al. A photoreceptor cell-specific ATP-binding transporter gene (ABCR) is mutated in recessive Stargardt macular dystrophy. Nat Genet 1997a;15:236-46.

20 Allikmets R, Shroyer NF, Singh N et al. Mutation of the Stargardt disease gene (ABCR) in age-related macular degeneration. Science 1997;277:1805-7.

21 Allikmets R, International ABCR Screening Consortium. Further evidence for an association of ABCR alleles with age-related macular degeneration. Am $\mathcal{f}$ Hum Genet 2000;67:487-91.

22 Rivera A, White K, Stöhr H, et al. A Comprehensive Survey of Sequence Variation in the ABCA4 (ABCR) Gene in Stargardt Disease and Age-Related Macular Degeneration. Am f Hum Genet 2000;67:800-13.

23 Souied EH, Ducroq D, Rozet JM, et al. ABCR gene analysis in familial exudative age-related macular degeneration. Invest Ophthalmol Vis Sci 2000;41:244-7.

24 Stöhr H, Mah N, Schulz HL, et al. EST mining of the UniGene dataset to identify retina-specific genes. Cytogenet Cell Genet (in press).

25 Nathans J, Hogness DS. Isolation, sequence analysis, and intron-exon arrangement of the gene encoding bovine rhodopsin. Cell 1983;34:807-14

26 Strader CD, Fong TM, Tota MR, et al. Structure and function of G protein-coupled receptors. Anпu Rev Biochem 1994;63:101-32.

27 Bracey LT, Paigen K. Changes in translational yield regulate tissue-specific expression of beta-glucuronidase. Proc Natl Acad Sci U S A 1987;84:9020-4.

28 Church GM, Gilbert W. Genomic sequencing. Proc Natl Acad Sci USA 1984;81:1991-5.

29 Fleiss JL. In: Statistical methods for rates and proportions. 2nd ed. New York: John Wiley, 1981.

30 Kozac M. Interpreting cDNA sequences: some insights from studies on translation. Mamm Genome 1996;7:56374

31 Tarttelin EE, Kirschner LS, Bellingham J, et al. Cloning and characterization of a novel orphan G-protein-coupled receptor localized to human chromosome $2 \mathrm{p} 16$. Biochem Biophys Res Comm 1999;260:174-80.

32 Marquardt A, Stöhr H, Passmore LA, et al. Mutations in a novel gene, VMD2, encoding a protein of unknown properties cause juvenile-onset vitelliform macular dystroproperties cause juvenile-onset vitelliform macular dyst

33 Petrukhin K, Koisti MJ, Bakall B et al. Identification of the gene responsible for Best macular dystrophy. Nature Genet 1998;19:241-7.

34 Allikmets R. Simple and Complex ABCR: genetic predisposition to retinal disease. Am f Hum Genet 2000;67:793-9. 